Research Article

\title{
Experimental Study on Initial Damage Point of Deep Granite under Step Cyclic Loading Method
}

\author{
Lu Chen, Shan Wu, and Lijie Guo \\ BGRIMM Technology Group, Beijing 102628, China \\ Correspondence should be addressed to Lijie Guo; guolijie@bgrimm.com
}

Received 25 August 2020; Revised 16 April 2021; Accepted 7 May 2021; Published 17 May 2021

Academic Editor: Payam Shafigh

Copyright (c $2021 \mathrm{Lu}$ Chen et al. This is an open access article distributed under the Creative Commons Attribution License, which permits unrestricted use, distribution, and reproduction in any medium, provided the original work is properly cited.

\begin{abstract}
In deep engineering, the initial damage point of host rock has become an important concern. Nowadays, there are many methods which can work out the initial damage point. However, each existing method introduces some significant subjective or parametric errors. In this paper, a new determination method of initial damage point employing step cyclic loading tests was designed and a series of tests were conducted on deep granite. After analyzing the peak strength and effect of cyclic loading, the turning point of initial damage was confirmed. The testing results show that the turning stress of initial damage was about $45 \%$ peak strength and will present a little decrease with the confining pressure increasing. These calculated damage points are much more scientific, accurate, and intuitive, which provides a new method for the study on rock mechanics in deep mining.
\end{abstract}

\section{Introduction}

For rock-based engineering projects, the damage characteristic of rocks is quite important. Furthermore, attentions must be paid to the initial damage point of rocks in these rock engineering projects, such as high-level radioactive wastes (HLW) disposal [13], hydropower stations [17], subways [10], soft-rock engineering [1], deep-buried tunnels [19], and mining engineering [11], to name a few. In general, the damage point is an inherent property of rock under single loading, independent of loading conditions. This point marks the beginning of rock damage, indicating subsequent crack formation and propagation, and is of great practical significance.

An increasing number of scholars have examined the damage point of rocks using laboratory tests. Brace et al. [2] monitored the volume variation of rock specimens. They thought that when rock was damaged, its volumetric strain would present nonlinear volume expansion, instead of linear development. Thus, the end point of linear volumetric strain is regarded as the damage point of rocks, and the solution process is shown in Figure 1(a). This method expresses clear physical meaning and convenient application, but the results are deeply influenced by the coordinate scale and discrete data. Taking the volumetric strain in Figure 1(a) as example, it is difficult to determine the No. 1 point, or the No. 2 point is the target point in the partial enlarged Figure 1(b). The confirmation of end point is subjective and arbitrariness. Lajtai [8] thought that the nonlinear lateral strain meant cracks expansion, so he took the beginning point of nonlinear growth in the axial stress-lateral strain curve as damage point (as shown in Figure 2(a)). Compared with the method proposed by Brace, the lateral strain method is much easier and more intuitive. However, it is undeniable that the lateral strain method also has some subjective factors and errors, and the same problem will affect the accuracy of the result. As the enlarged crack volumetric curve shown in Figure 2(b), there will also be some deviations in the determination results under different data curve scales, the initial damage point can be confirmed as point 1 , and the other damage point can be selected as point 3 in Figure 2(b). Martin and Chandler [12] conducted a large number of triaxial compression tests on granite samples from mine-by tunnel in Canada. By summarizing the strength relationship of granite samples, they proposed that the stress when the crack volume strain is not zero at first could be treated as the damage point. The accuracy of calculation through this method is largely dependent on the accuracy of elastic 


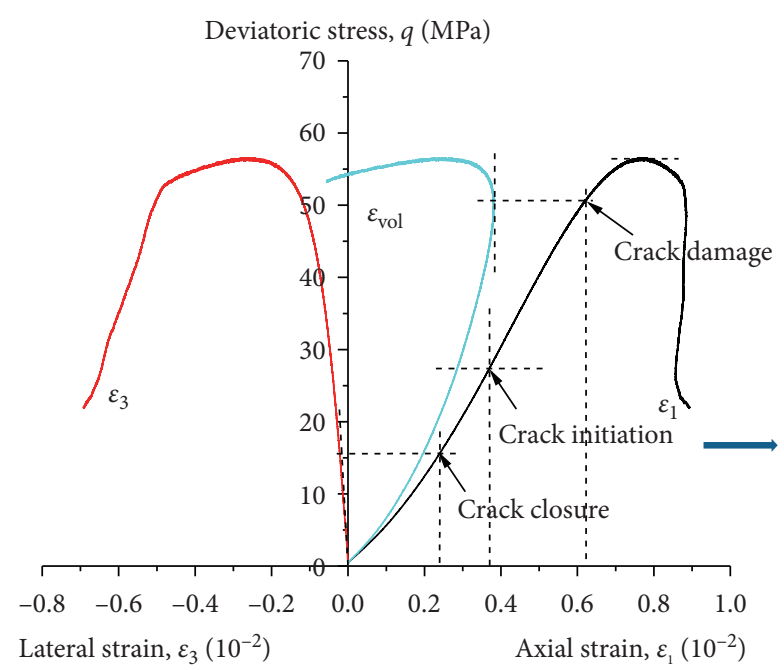

(a)

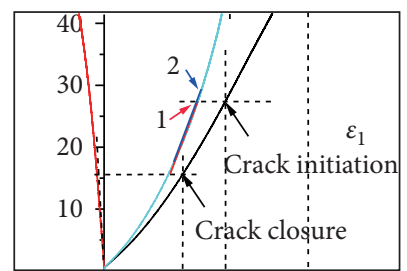

(b)

Figure 1: Damage threshold confirming curves by Brace's method: (a) the damage point of rocks; (b) the subjective error analysis [16].

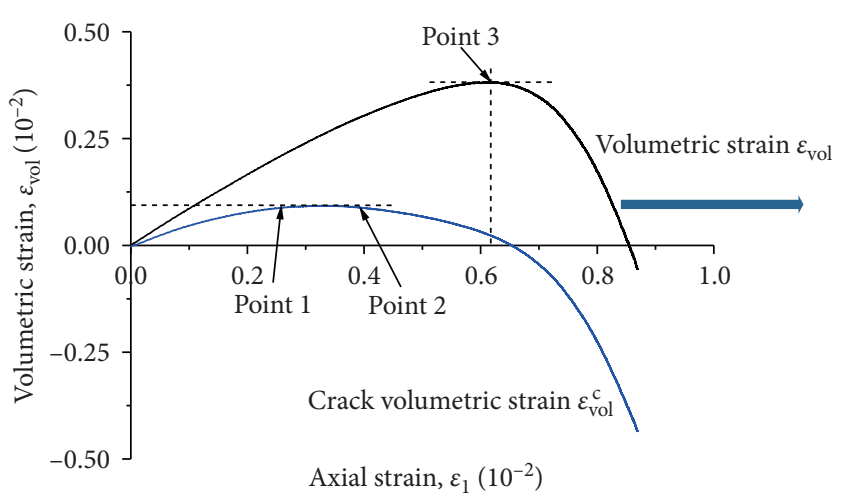

(a)

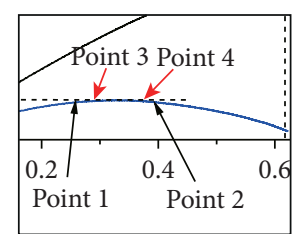

(b)

FIgURE 2: Typical damage threshold confirming curves by the Lajtai method: (a) the damage point of rocks; (b) the subjective error analysis [16].

modulus and Poisson's ratio of rock, and there are still errors in the calculation of elastic modulus and Poisson's ratio, which also makes this method highly subjective. Studies show that the failure process of rocks is accompanied by the release of acoustic emission (AE) signals. Through monitoring the AE signal strength, the damage process of rocks can be visually obtained. Therefore, various studies on rock stress are carried out by acoustic emission monitoring. Eberhardt et al. [4] identified the crack initiation and propagation thresholds in brittle rock by $\mathrm{AE}$ monitoring; Ganne and Vervoort [5] confirmed the effect of stress path on pre-peak damage with AE method; Nejati and Ghazvinian [15] studied the brittleness effect during rock fatigue damage process by employing AE equipment; Kim et al. [7] carried out a comparative evaluation of stress-strain and $\mathrm{AE}$ methods for quantitative damage assessments of brittle; Zhao et al. [23] analyzed the rock damage characteristics based on the AE monitoring data. It is assumed that the first $\mathrm{AE}$ count mutation corresponds to the damage point of rock.
AE techniques provide scientific method for exploring rock fracture process, but this method still has subjective errors, noise interference, and absence of theoretical basis [21]. The initial AE records during loading can be related to the setting of loading platens on the specimen, machine displacement, instrument vibration, and other influence factors. It is difficult to determine which AE count is the correct index which corresponds to the damage point of rock.

In order to avoid the shortage of the above methods, a new step cyclic loading test was designed. Some scholars have conducted experiments on rocks under cyclic loading. Yang et al. [18] studied the mechanical property of sandstone post-peak under the cyclic loading and unloading; Zhang et al. [20] carried out the lab tests on damage characteristics of sandstone subjected to pre-peak and postpeak cyclic loading; Munoz and Taheri [14] analyzed the post-peak deformability parameters of rocks under cyclic loading. These studies can provide good experimental ideas and schemes for reference. In this paper, taking advantage of 
MTS815 rock experimental equipment, the step cyclic loading tests with increasing stress were conducted on deep granite from Sanshandao Gold Mine, China. And, a more accurate initial damage point under confining pressures of $10 \mathrm{MPa}, 20 \mathrm{MPa}$, and $30 \mathrm{MPa}$ was confirmed. The calculated initial damage points are much more scientific and intuitive, which provides a new method for the study on rock mechanics in deep mining engineering.

\section{Testing Scheme}

2.1. Granite Samples and Basic Parameters. In the tests, the rock specimen is granite, drilled from -895 level of Sanshandao Gold Mine (Shandong Province, China), with the mineral composition of quartz, anorthose, biotite, and alkali feldspar. The density of rock samples is $2.72 \mathrm{~g} / \mathrm{cm}^{3}$, and the porosity is $0.59 \%$. All the rock samples were cut from a whole block rockmass without any obvious cracks. According to the proposed approach of ISRM [6], the allowed deviation of roughness at the two ends for the specimen is $\pm 0.05 \mathrm{~mm}$, and the allowed perpendicularity deviation is $\pm 0.25^{\circ}$. In the tests, 36 standard rock samples with $50 \mathrm{~mm}$ diameter and $100 \mathrm{~mm}$ height were acquired, as shown in Figure 3.

2.2. Experimental Installation. In the step cyclic loading tests, the MTS 815 testing system was adopted, as shown in Figure 4. For this MTS 815 testing system, the maximum axial loading can reach $2700 \mathrm{kN}$, and the maximum confining pressure is $140 \mathrm{MPa}$. The strain of rock samples could be monitored by the axial and lateral extensometers, with the largest testing ranges of $5 \mathrm{~mm}$ and $8 \mathrm{~mm}$ in axial and lateral direction, respectively. And, during the loading process, to avoid the effect of hydraulic oil, the heat shrinkable tube was employed to encircle the granite sample. At the same time, the lubricant was spread on the two ends of samples to decrease the ends' effect.

2.3. ExperimentalDesign. Firstly, to obtain the basic strength and other mechanical parameters of granite, a set of triaxial compressive tests with different confining pressures (10 MPa, $20 \mathrm{MPa}$, and $30 \mathrm{MPa}$ ) were carried out. During the tests, the AE event will be monitored by $\mathrm{AE}$ instrument, and the key parameters of $\mathrm{AE}$ instrument related to the measurement are shown in Table 1. The obtained stress thresholds can be conducted for the comparative analysis with next ascending step cyclic loading testing results. The testing programs are as follows: apply the confining pressure to the design value, with the loading rate of $0.25 \mathrm{MPa} / \mathrm{s}$; next, apply axial loading until the granite specimen is completely damaged; the axial loading is controlled by deformation at $0.024 \mathrm{~mm} / \mathrm{min}$. The stress and strain data were recorded during the whole testing process. The testing results are listed in Table 2.

Secondly, to evaluate the effect degree of cyclic loading on the rock strength and to confirm the initial value of next ascending step cyclic loading tests, two kinds of cyclic loading tests up to $20 \%$ peak strength and $40 \%$ peak strength were implemented. A large number of studies showed that the ratio of crack initiation stress to peak stress is about or a little bigger than $40 \%$ peak strength [3], so the $40 \%$ cyclic loading tests could give an approximate threshold of ascending step cyclic loading tests. For the $20 \%$ cyclic loading test, its results can verify whether specimens in $40 \%$ cyclic loading test are always in the elastic stage. The testing programs are as follows: apply the confining pressure to design value, with the loading rate of $0.25 \mathrm{MPa} / \mathrm{s}$; apply axial loading to a certain value (about $20 \% \sigma_{\mathrm{P}}$ or $40 \% \sigma_{\mathrm{P}}$ ) with the loading rate of $0.5 \mathrm{kN} / \mathrm{s}$; unload to $2 \mathrm{MPa}$ at the same rate $(0.5 \mathrm{kN} / \mathrm{s})$; repeat the above cyclic steps 5 times for one sample and record the stress and strain data during the whole testing process. The loading process is shown in Figure 5(a). The testing data is listed in Table 3.

Thirdly, based on the above confirmed initial range of the elastic stage, the ascending step cyclic loading tests were conducted, to determine the accurate initial damage point of deep granite. In the increasing process of loading, if the ending point of two cyclic curves is different, it is considered that the samples are damaged. The detailed testing program is as follows: apply the confining pressure to design value, with the loading rate of $0.25 \mathrm{MPa} / \mathrm{s}$; apply axial loading from about $40 \% \sigma_{\mathrm{P}}$, with the loading rate of $0.5 \mathrm{kN} / \mathrm{s}$; unload to $2 \mathrm{MPa}$ at the same rate $(0.5 \mathrm{kN} / \mathrm{s})$; repeat this cyclic loading process with ascending axial loading (about 42\%, 44\%, 46\% $\sigma_{\mathrm{P}} \ldots . .$. , respectively), as shown in Figure 5(b); in this cyclic process, monitor the stress and strain data; if the end point of two cyclic process are different, apply axial loading with $0.024 \mathrm{~mm} / \mathrm{min}$, until the granite specimen is completely damaged. The detailed testing data is listed in Table 4 .

\section{Testing Results and Data Analysis}

After the triaxial compression tests under three confining pressures (10 $\mathrm{MPa}, 20 \mathrm{MPa}$, and $30 \mathrm{MPa})$, the stress-strain curves are shown in Figure 6.

The triaxial compression strength of deep granite samples can be acquired from Figure 6. The detailed values are shown in Table 2. And, the typical corresponding AE data was shown in Figure 7. After data analyzing, the initial crack stress thresholds are $153 \mathrm{MPa}, 186 \mathrm{MPa}$, and $215 \mathrm{MPa}$ for the confining pressure of $10 \mathrm{MPa}, 20 \mathrm{MPa}$, and $30 \mathrm{MPa}$, respectively.

In addition, by analyzing the stress-strain curves, the elasticity modulus can also be calculated following the method in Figure 8. Here, the elasticity modulus values are $73.06 \mathrm{GPa}, 76.35 \mathrm{GPa}$, and $78.94 \mathrm{GPa}$, respectively, with computational formula in the ISRM suggestion method [6]:

$$
E=\frac{\sigma_{l_{-} \text {begin }}-\sigma_{l_{-} \text {end }}}{\varepsilon_{l_{-} \text {begin }}-\varepsilon_{l_{-} \text {end }}},
$$

where $E$ is the elasticity modulus, $\sigma_{l_{-} \text {begin }}$ and $\sigma_{l_{-} \text {end }}$ are the beginning and ending values of stress in linear stress-strain curve segment, and $\varepsilon_{l_{-} \text {begin }}$ and $\varepsilon_{l_{-} \text {end }}$ are the beginning and ending values of strain in linear stress-strain curve segment.

The triaxial compressive tests provide basic mechanical parameters of granite samples. Following the testing program in Table 3 and Figure 5(a), 6 groups of loading and 


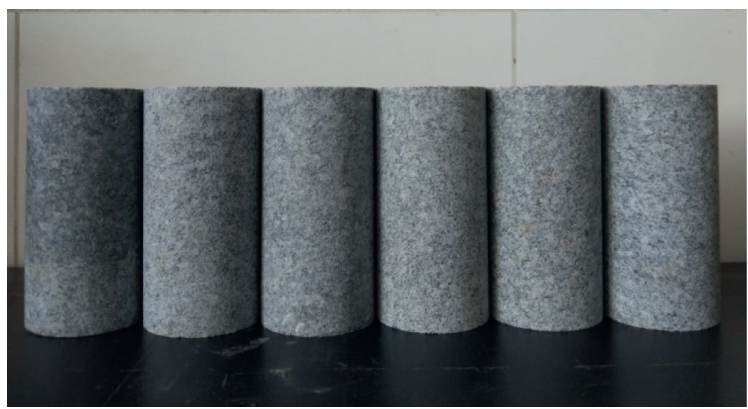

FIgURE 3: The granite samples and its optical image.

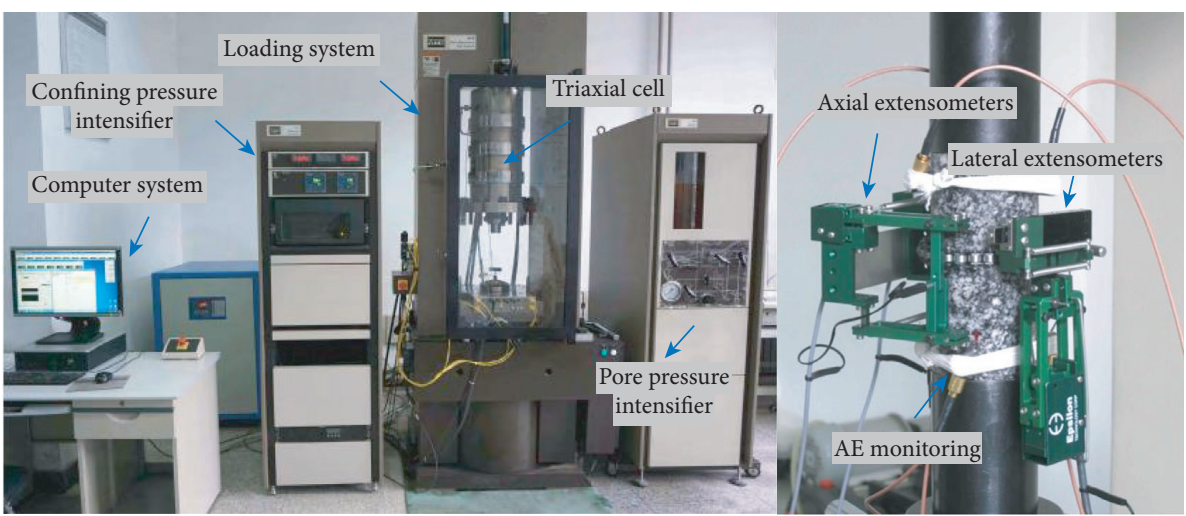

FIGURE 4: MTS 815 rock mechanics apparatus.

TABle 1: The key parameters of AE instrument related to the measurement.

\begin{tabular}{lccccc}
\hline $\begin{array}{l}\text { Data transmission speed } \\
(\mathrm{MB} / \mathrm{s})\end{array}$ & $\begin{array}{c}\text { Sampling accuracy } \\
(\text { byte })\end{array}$ & $\begin{array}{c}\text { Recording frequency } \\
(\mathrm{kHz})\end{array}$ & $\begin{array}{c}\text { Recording length } \\
(\text { byte })\end{array}$ & $\begin{array}{c}\text { Recording interval } \\
(\text { byte })\end{array}$ & $\begin{array}{c}\text { Detection threshold } \\
(\mathrm{dB})\end{array}$ \\
\hline 132 & 16 & 2000 & 2048 & 2048 & 40 \\
\hline
\end{tabular}

TABLE 2: Testing results of triaxial compression tests.

\begin{tabular}{lcc}
\hline Testing no. & Confining pressure $(\mathrm{MPa})$ & Peak strength $\sigma_{P}(\mathrm{MPa})$ \\
\hline G-10-1 & 10 & 328 \\
G-20-1 & 20 & 402 \\
G-30-1 & 30 & 461 \\
\hline
\end{tabular}

unloading tests with $20 \% \sigma_{\mathrm{P}}$ and $40 \% \sigma_{\mathrm{P}}$ fixed values and $10 \mathrm{MPa}, 20 \mathrm{MPa}$, and $30 \mathrm{MPa}$ confining pressures were carried out. Here, the typical stress-strain curves are drawn in Figure 9.

As exhibited in Figure 9, after 5 times loading and unloading process cycles, for all testing conditions, the unloading curves all show good overlap, which means there is not any fatigue damage after 5 cycles, and the whole testing processes are all under elastic status. It also indicates that the initial damage point of granite must occur over $40 \% \sigma_{\mathrm{P}}$. These tests' results give guidance for the next ascending step cyclic tests.

After confirming the approximate range of initial damage point, 3 groups ascending cyclic loading tests were carried out, with loading conditions over $40 \% \sigma_{\mathrm{P}}$. After the test, the stress and strain curves of step cyclic loading tests with different confining pressure could be obtained. Taking $10 \mathrm{MPa}$ confining pressure testing data as example, the data processing step is shown in Figure 10.

As shown in Figure 10, based on the testing data, the step cyclic loading curve of stress and strain could be fitted and is shown in Figure 10(a). During the step cyclic loading tests, if the two unloading curves begin to separate, meaning that the input energy supplied by MTS 815 testing system is consumed by the rock samples, it can be assumed that the granite sample begins to enter damage status from this stress. So, the unloading curve which begins to separate was the target unloading curve (the pink curve in Figure 10(b)); also, the corresponding loading curve could be found (the red curve in Figure 10(c)). To acquire accurate damage threshold, the key segment data of target loading curve was obtained and fitted separately, as shown in Figure 10(d). In Figure $10(\mathrm{~d})$, since the rock sample began to damage, the stress-strain curve would no longer be linear; there would be a turning point, which is the initial damage point. Under $10 \mathrm{MPa}$ confining pressure, the turning point appears at $147 \mathrm{MPa}$ stress value.

Other stress-strain curves with $20 \mathrm{MPa}$ and $30 \mathrm{MPa}$ confining pressure are illustrated in Figures 11(a) and 11(b), respectively. 


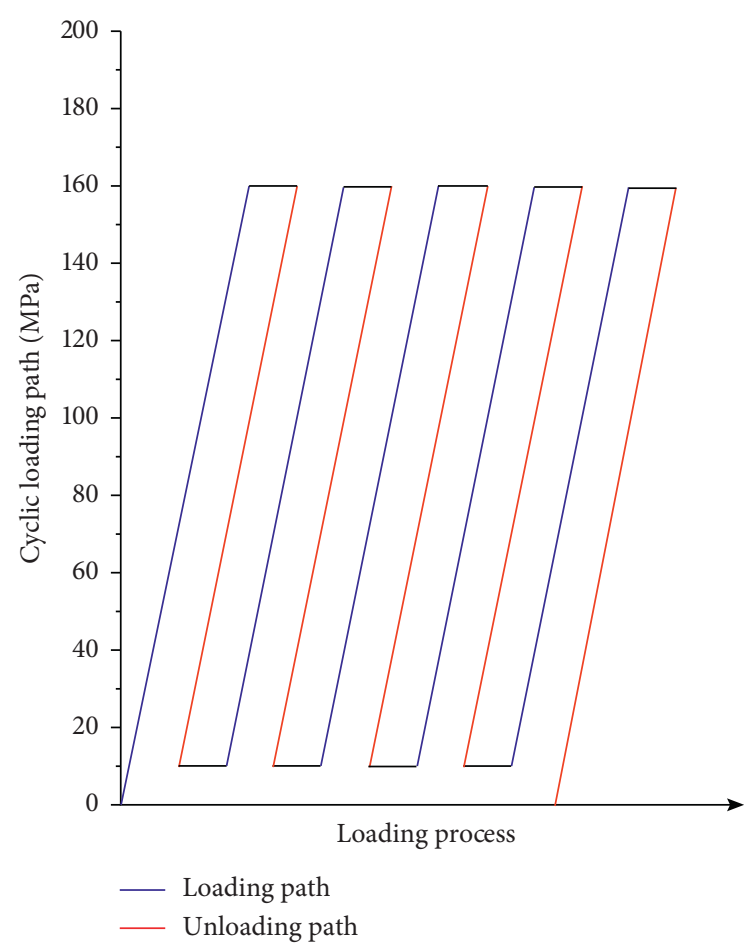

(a)

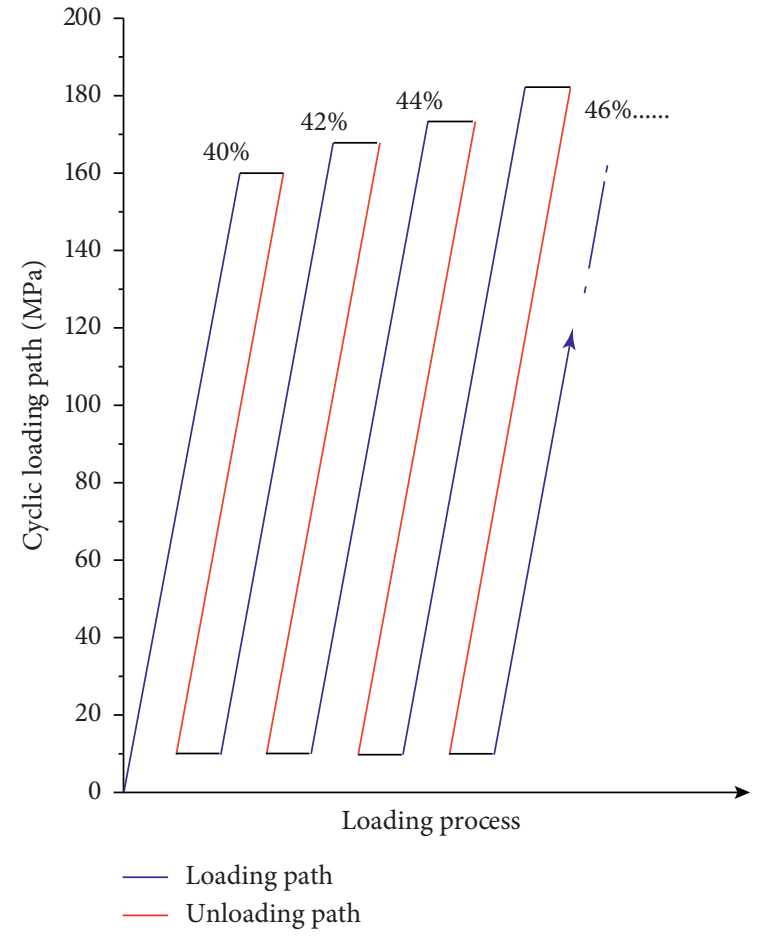

(b)

Figure 5: The schematic diagram of loading process: (a) the path of cyclic loading tests; (b) the path of ascending step cyclic loading tests.

TABle 3: Testing data of preliminary cyclic loading tests.

\begin{tabular}{lccc}
\hline Testing no. & Confining pressure $(\mathrm{MPa})$ & Axial loading $(\mathrm{MPa})$ & Percentage of $\sigma_{P}(\%)$ \\
\hline G-10-C1 & 10 & 65 & 20 \\
G-10-C2 & 10 & 131 & 40 \\
G-20-C1 & 20 & 80 & 20 \\
G-20-C2 & 20 & 160 & 40 \\
G-30-C1 & 30 & 92 & 20 \\
G-30-C2 & 30 & 184 & 40 \\
\hline
\end{tabular}

TABle 4: Program of ascending step cyclic loading tests.

\begin{tabular}{|c|c|c|c|c|c|c|c|c|c|}
\hline \multirow[t]{2}{*}{ Testing no. } & \multirow{2}{*}{ Confining pressure (MPa) } & \multicolumn{2}{|c|}{$\begin{array}{c}\text { Initial axial } \\
\text { loading }(\mathrm{MPa})\end{array}$} & \multicolumn{6}{|c|}{ Ascending axial loading $(\mathrm{MPa})$} \\
\hline & & Value & Pct. & Value & Pct. & Value & Pct. & Value & Pct. (\%) \\
\hline G-10-X1 & 10 & 131 & 40 & 137 & 42 & 144 & 44 & 151 & 46 \\
\hline G-20-X1 & 20 & 160 & 40 & 169 & 42 & 177 & 44 & 185 & 46 \\
\hline G-30-X1 & 30 & 184 & 40 & 193 & 42 & 203 & 44 & 212 & 46 \\
\hline
\end{tabular}

From Figures 10 and 11, the peak strengths under different confining pressure are $311 \mathrm{MPa}, 408 \mathrm{MPa}$, and $472 \mathrm{MPa}$, which are almost the same with that of the aforementioned triaxial compression testing results (328 MPa, $402 \mathrm{MPa}$, and $461 \mathrm{MPa}$, as shown in Figure 6). The slight errors maybe produced by the instrument, testing process, or different granite samples. These good verified results also testify that the cyclic loading process produce no effect on the strength characteristics of granite. After calculation with the method shown in Figure 10, the initial damage stress thresholds confirmed by cyclic tests are shown in Table 5. The initial damage points are $47.2 \% \sigma_{\mathrm{p}}$ for $10 \mathrm{MPa}, 44.4 \% \sigma_{\mathrm{P}}$ for $20 \mathrm{MPa}$, and $43.8 \% \sigma_{\mathrm{P}}$ for $30 \mathrm{MPa}$, respectively.

\section{Discussion}

The initial damage points confirmed by the step cyclic loading method show that the turning stress of initial damage is about $45 \%$ peak strength on average. It is similar to the crack initiation thresholds for shale by Li et al. [9] and Beishan granite by Zhao et al [22] confirmed by the AE 


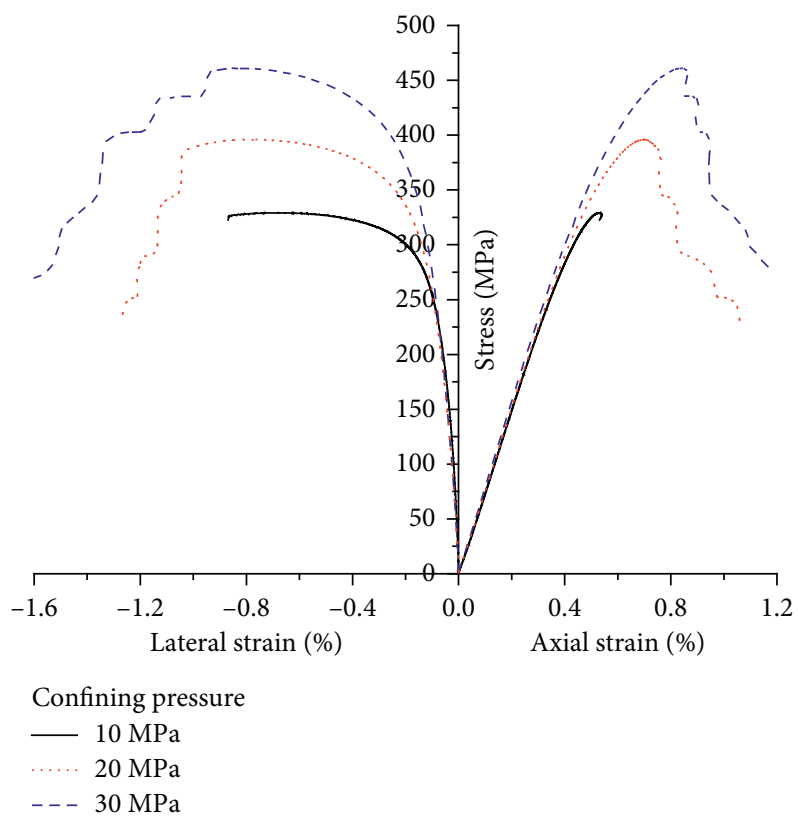

Figure 6: Stress-strain curves under three different confining pressures.

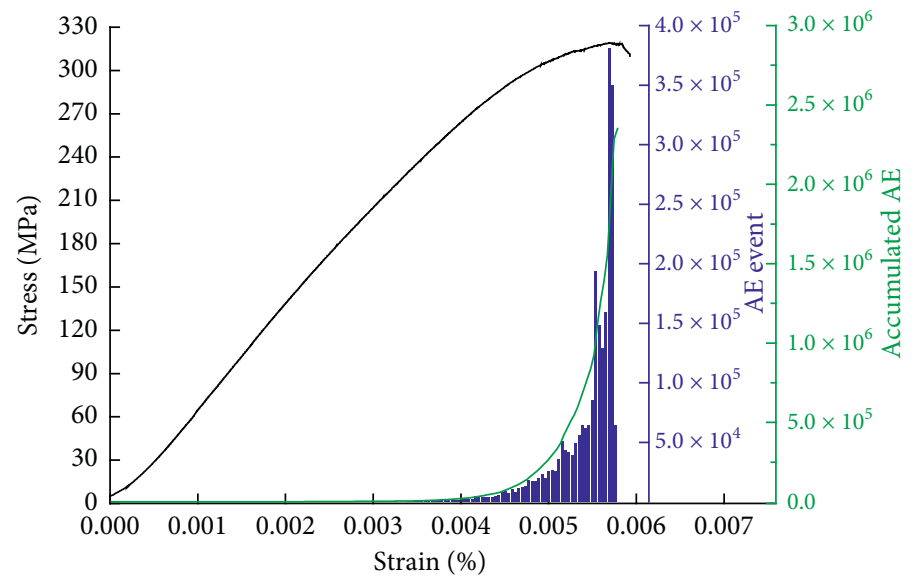

(a)

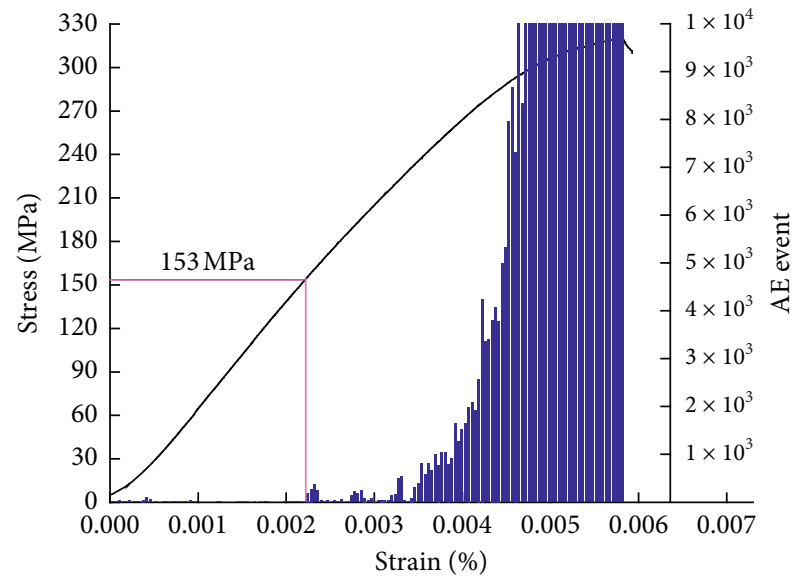

(b)

Figure 7: Typical AE monitoring data and stress-strain curve: (a) AE monitoring data and stress-strain curves; (b) AE data and corresponding initial crack stress thresholds.

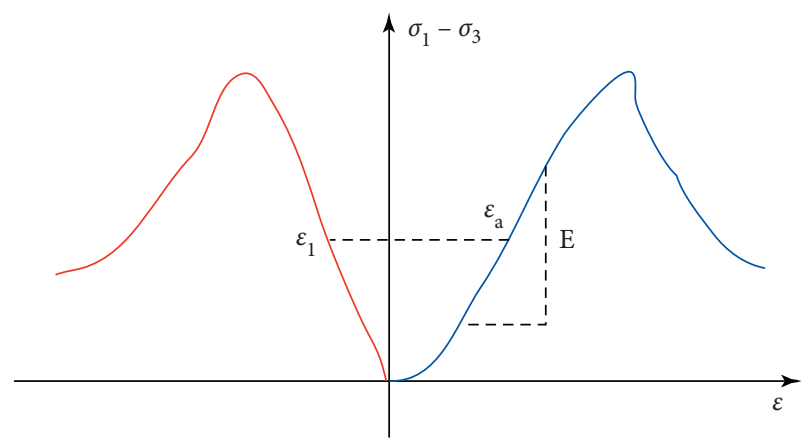

Figure 8: The schematic diagram for elasticity modulus calculation. testing method. And, the testing result in this paper presents a little decrease with the increasing of confining pressure. To verify and analyze the step cyclic testing data, the AE testing results are also listed in Table 5.

As shown in Table 5, the stress values determined by two testing methods (initial damage stress by cyclic test and initial crack stress by the AE method) are not far apart under the same confining pressure, and the percentage of difference is below $5 \%$. However, the results confirmed by cyclic loading tests have much clearer physical meaning and less error of the combination of two instruments. Therefore, the cyclic testing method has more credibility than the $\mathrm{AE}$ monitoring method. 


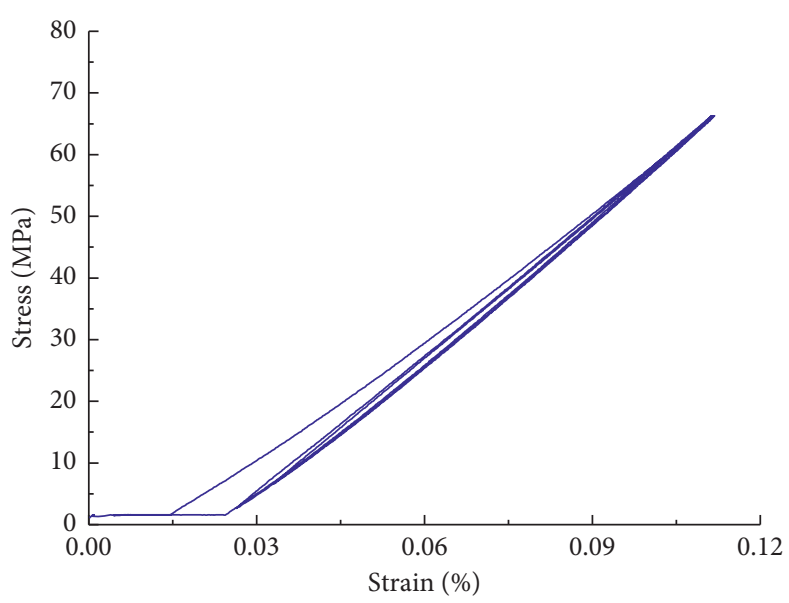

(a)

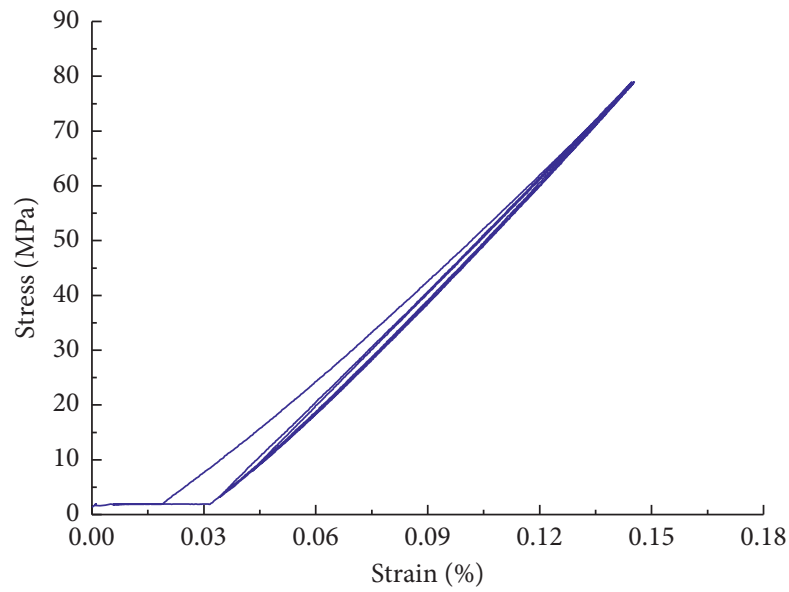

(c)

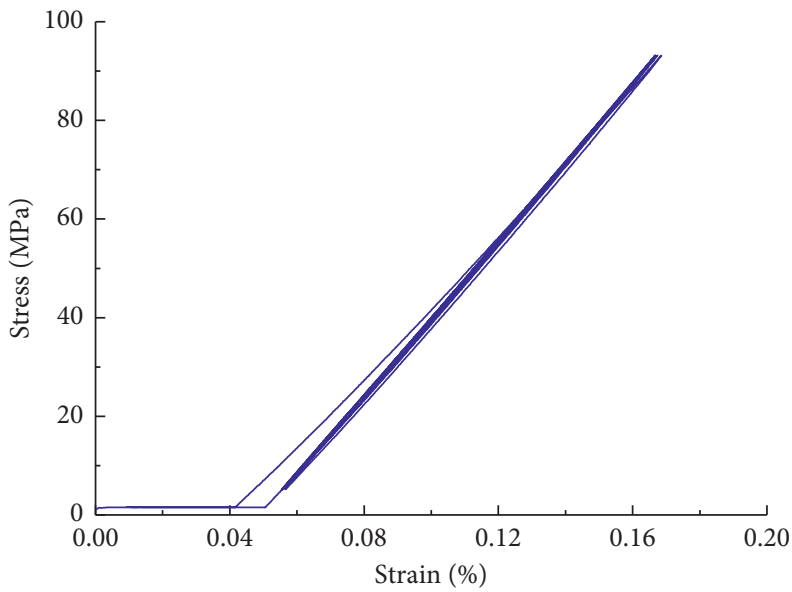

(e)

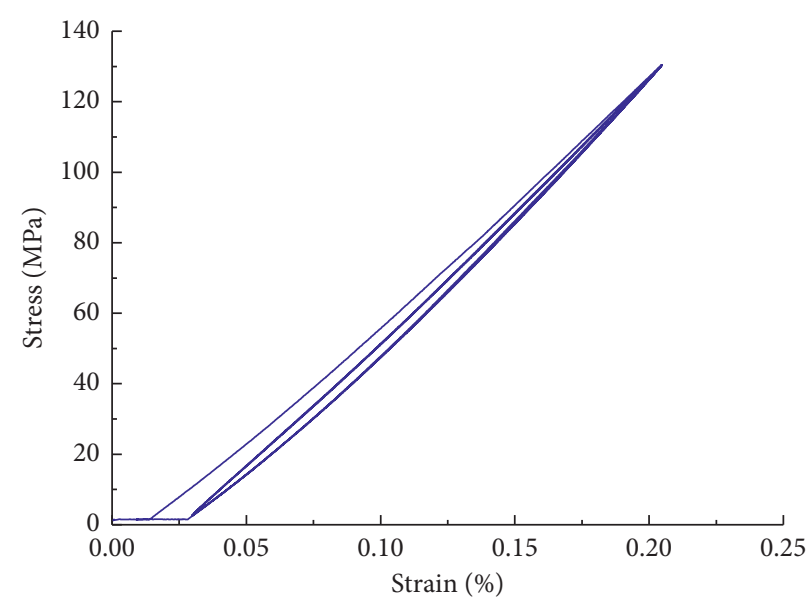

(b)

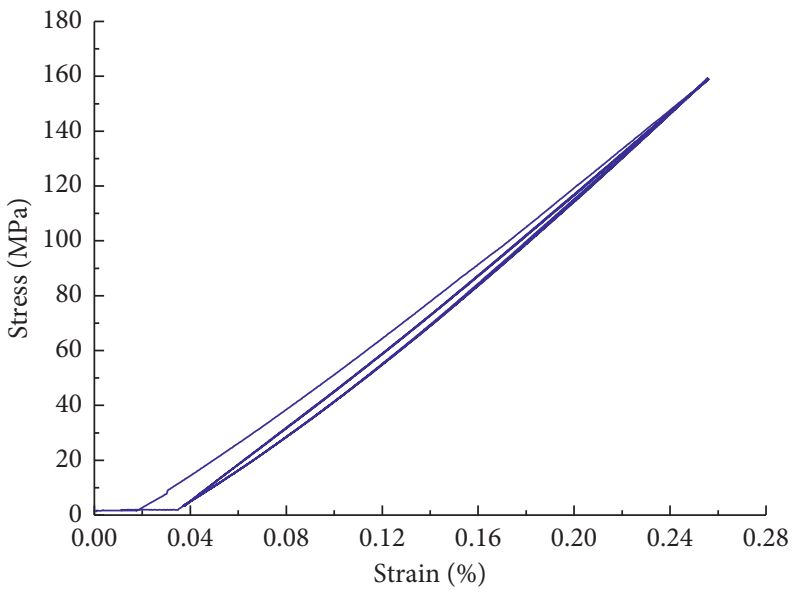

(d)

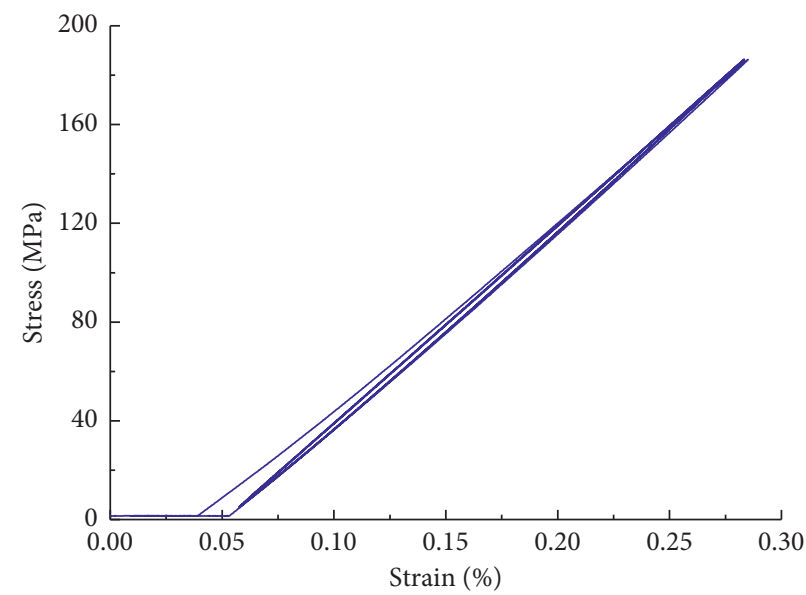

(f)

Figure 9: Typical stress-strain curves under different fixed values and confining pressures: (a) $20 \% \sigma \mathrm{P}$ and $10 \mathrm{MPa}$; (b) $40 \% \sigma_{\mathrm{P}}$ and $10 \mathrm{MPa}$; (c) $20 \% \sigma_{\mathrm{P}}$ and $20 \mathrm{MPa}$; (d) $40 \% \sigma_{\mathrm{P}}$ and $20 \mathrm{MPa}$; (e) $20 \% \sigma_{\mathrm{P}}$ and $30 \mathrm{MPa}$; (f) $40 \% \sigma_{\mathrm{P}}$ and $30 \mathrm{MPa}$. 


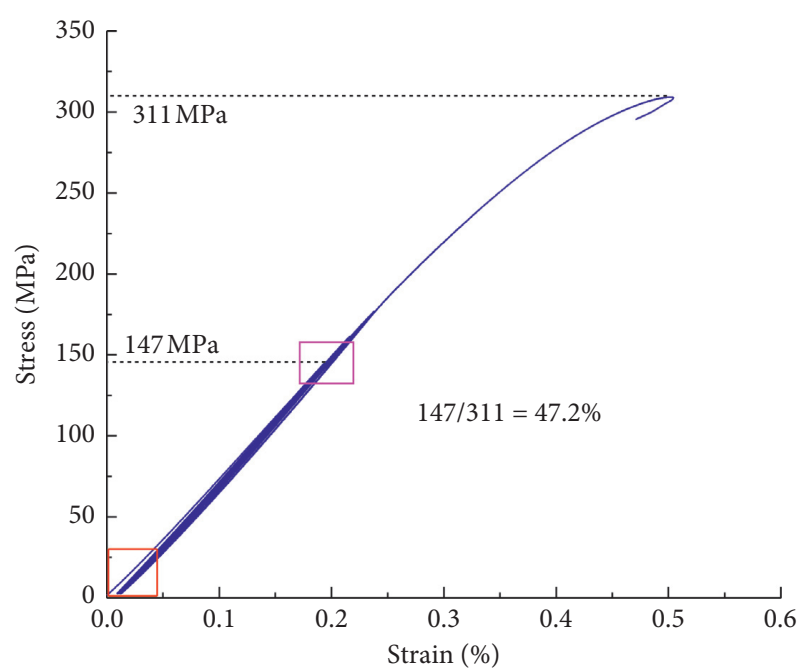

(a)

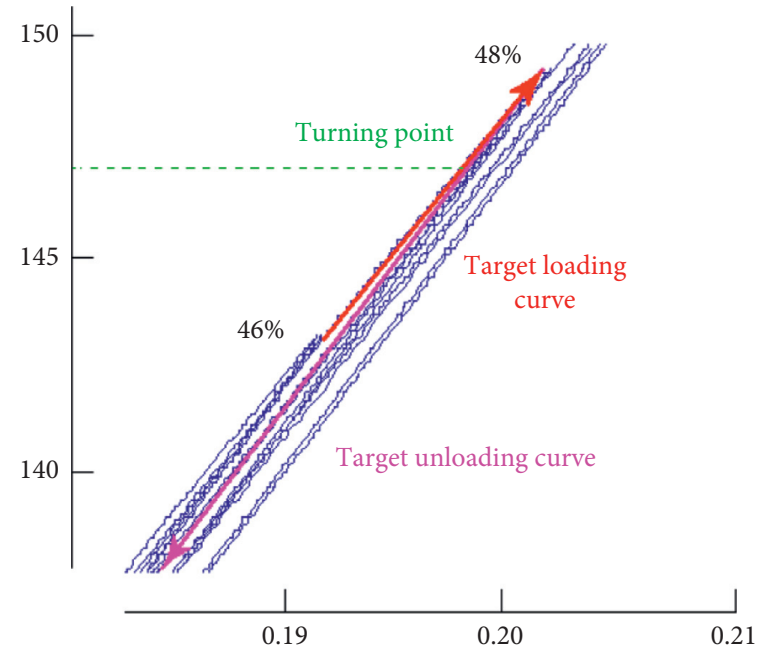

(c)

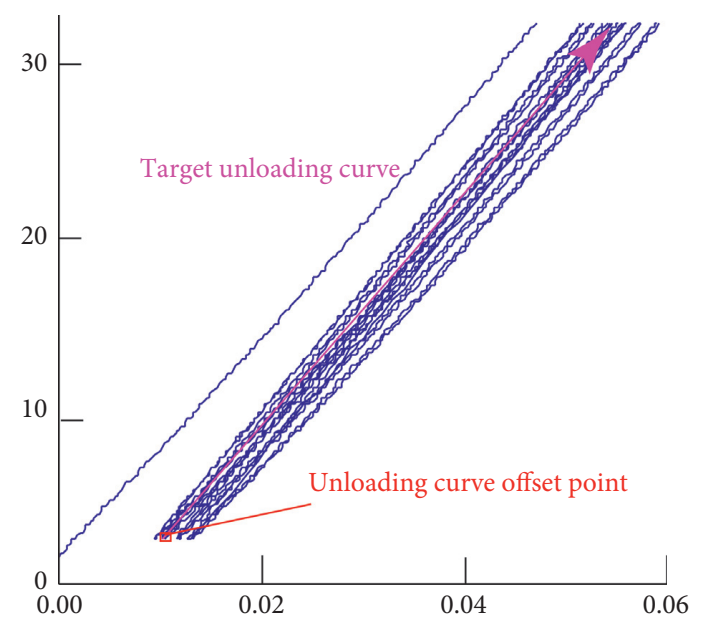

(b)

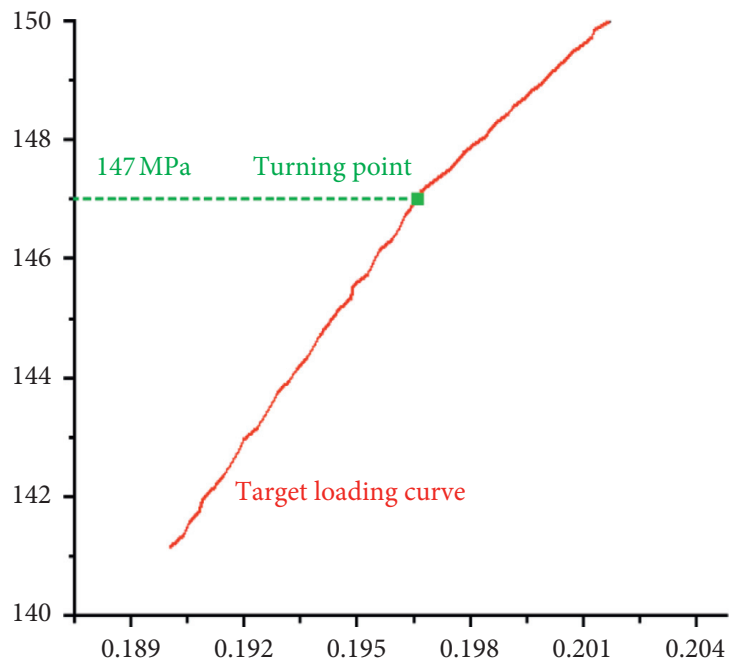

(d)

Figure 10: Data processing step of damage threshold with $10 \mathrm{MPa}$ confining pressure: (a) the stress-strain curves in ascending step cyclic loading under $10 \mathrm{MPa}$ confining pressure; (b) target unloading curve evaluated process; (c) target loading curve evaluated process; (d) initial damage point evaluated process. 


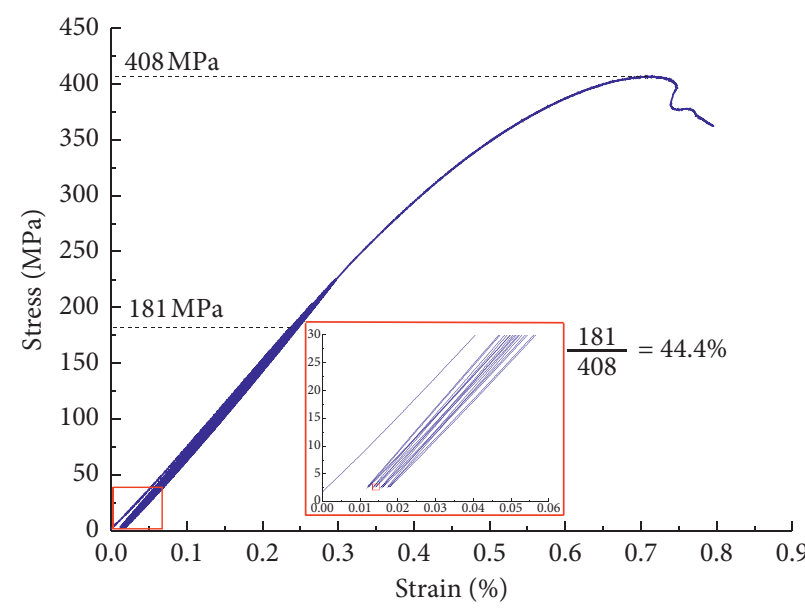

(a)

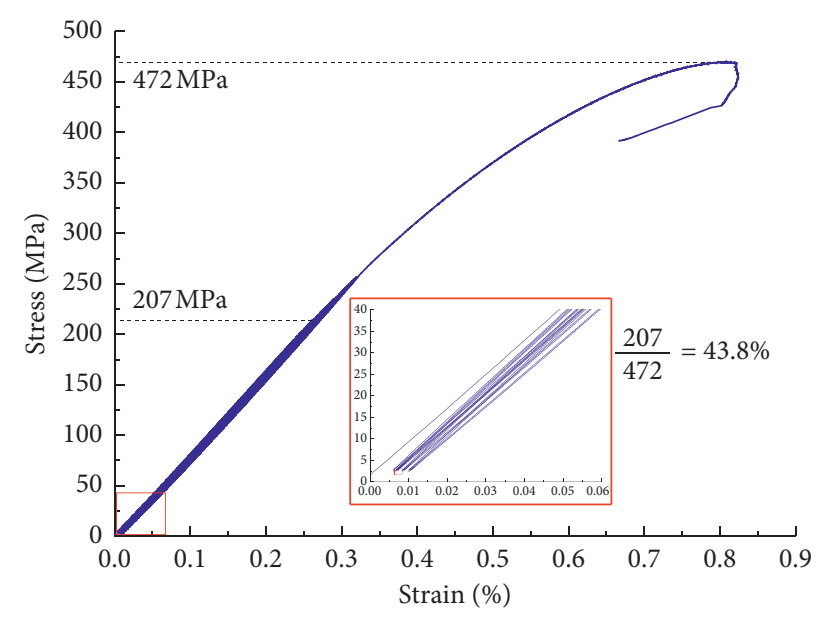

(b)

FIGURE 11: Stress-strain curves in ascending step cyclic loading tests: (a) initial damage point under $20 \mathrm{MPa}$ confining pressure; (b) initial damage point under $30 \mathrm{MPa}$ confining pressure.

TABLE 5: Initial damage stress by cyclic test and initial crack stress by the AE method.

\begin{tabular}{lccc}
\hline Confining pressure $(\mathrm{MPa})$ & Initial damage stress by cyclic test $(\mathrm{MPa})$ & Initial crack stress by AE method (MPa) & Difference value (\%) \\
\hline 10 & 147 & 153 & 4.08 \\
20 & 181 & 186 & 2.76 \\
30 & 207 & 215 & 3.86 \\
\hline
\end{tabular}

\section{Conclusions}

The initial damage point of rock is an important parameter in rock-based engineering. In this paper, by employing a series of scientific laboratory tests, a much more accurate and intuitive initial damage point of deep granite from Sanshandao Gold Mine was confirmed, which provides a new method and scientific data for the study on rock mechanics in deep mining.

Through triaxial compression tests, the peak strength, elasticity modulus, and other basic mechanical parameters of granite samples were acquired. On this basis, cyclic loading tests with $20 \%$ peak strength and $40 \%$ peak strength were carried out. Results show that, under these stress conditions, all the specimens are under elastic status, and the initial damage point of granite must occur over $40 \% \sigma_{\mathrm{P}}$.

Finally, taking advantage of ascending step cyclic loading tests, the accurate initial damage points of deep granite were acquired. The exact values are $47.2 \% \sigma_{\mathrm{P}}$ for $10 \mathrm{MPa}, 44.4 \% \sigma_{\mathrm{P}}$ for $20 \mathrm{MPa}$, and $43.8 \% \sigma_{\mathrm{P}}$ for $30 \mathrm{MPa}$, respectively. The testing results show that the turning stress of initial damage is about $45 \%$ peak strength on average, and it presents a little decrease with the increasing of confining pressure.

\section{Data Availability}

All data used to support the findings of this study are available from the corresponding author upon request.

\section{Conflicts of Interest}

The authors declare that they have no conflicts of interest.

\section{Acknowledgments}

This work was financially supported by the State Key Research Development Program of China (no. 2018YFE0123000), Youth Science and Technology Innovation Fund of BGRIMM Technology Group (no. 04-2001), and Fund for opening Key Laboratories of the Ministry of Education (no. Ustbmslab201905).

\section{References}

[1] K. Bian, J. Liu, W. Zhang, X. Zheng, S. Ni, and Z. Liu, "Mechanical behavior and damage constitutive model of rock subjected to water-weakening effect and uniaxial loading," Rock Mechanics and Rock Engineering, vol. 52, no. 1, pp. 97-106, 2019.

[2] W. F. Brace, B. W. Paulding, and C. H. Scholz, "Dilatancy in the fracture of crystalline rocks," Journal of Geophysical Research, vol. 71, no. 16, pp. 3939-3953, 1996.

[3] M. Cai, P. K. Kaiser, Y. Tasaka, T. Maejima, H. Morioka, and M. Minami, "Generalized crack initiation and crack damage stress thresholds of brittle rock masses near underground excavations," International Journal of Rock Mechanics and Mining Sciences, vol. 41, no. 5, pp. 833-847, 2004. 
[4] E. Eberhardt, D. Stead, B. Stimpson, and R. S. Read, "Identifying crack initiation and propagation thresholds in brittle rock," Canadian Geotechnical Journal, vol. 35, no. 2, pp. 222-233, 1998.

[5] P. Ganne and A. Vervoort, "Effect of stress path on pre-peak damage in rock induced by macro-compressive and -tensile stress fields," International Journal of Fracture, vol. 144, no. 2, pp. 77-89, 2007.

[6] ISRM, Suggested Methods for Determining the Strength of Rock Materials in Triaxial Compression: Revised Version, pp. 285290, ISRM: Suggested Methods for Triaxial Compression Testing, Bangalore, India, 1983.

[7] J.-S. Kim, K.-S. Lee, W.-J. Cho, H.-J. Choi, and G.-C. Cho, “A comparative evaluation of stress-strain and acoustic emission methods for quantitative damage assessments of brittle rock," Rock Mechanics and Rock Engineering, vol. 48, no. 2, pp. 495-508, 2015.

[8] E. Z. Lajtai, "Brittle fracture in compression," International Journal of Fracture, vol. 10, no. 4, pp. 525-536, 1974.

[9] C. Li, H. Xie, and J. Wang, "Anisotropic characteristics of crack initiation and crack damage thresholds for shale," International Journal of Rock Mechanics and Mining Sciences, vol. 126, Article ID 104178, 2020.

[10] T.-C. Li, L.-X. Lyu, S.-L. Zhang, and J.-C. Sun, "Development and application of a statistical constitutive model of damaged rock affected by the load-bearing capacity of damaged elements," Journal of Zhejiang University-Science A, vol. 16, no. 8, pp. 644-655, 2015.

[11] J.-P. Liu, Y.-H. Li, and S.-D. Xu, "Estimation of cracking and damage mechanisms of rock specimens with precut holes by moment tensor analysis of acoustic emission," International Journal of Fracture, vol. 188, no. 1, pp. 1-8, 2014.

[12] C. D. Martin and N. A. Chandler, "The progressive fracture of Lac du Bonnet granite," International Journal of Rock Mechanics and Mining Sciences \& Geomechanics Abstracts, vol. 31, no. 6, pp. 643-659, 1994.

[13] C. Müller, T. Frühwirt, D. Haase, R. Schlegel, and H. Konietzky, "Modeling deformation and damage of rock salt using the discrete element method," International Journal of Rock Mechanics and Mining Sciences, vol. 103, pp. 230-241, 2018.

[14] H. Munoz and A. Taheri, "Postpeak deformability parameters of localized and nonlocalized damage zones of rocks under cyclic loading," Geotechnical Testing Journal, vol. 42, pp. 1663-1684, 2019.

[15] H. R. Nejati and A. Ghazvinian, "Brittleness effect on rock fatigue damage evolution," Rock Mechanics and Rock Engineering, vol. 47, no. 5, pp. 1839-1848, 2014.

[16] A. Taheri, Y. Zhang, and H. Munoz, "Performance of rock crack stress thresholds determination criteria and investigating strength and confining pressure effects," Construction and Building Materials, vol. 243, Article ID 118263, 2020.

[17] N. W. Xu, F. Dai, Z. Z. Liang, Z. Zhou, C. Sha, and C. A. Tang, "The dynamic evaluation of rock slope stability considering the effects of microseismic damage," Rock Mechanics and Rock Engineering, vol. 47, no. 2, pp. 621-642, 2014.

[18] D. Yang, D. Zhang, S. Niu, Y. Dang, W. Feng, and S. Ge, "Experiment and study on mechanical property of sandstone post-peak under the cyclic loading and unloading," Geotechnical and Geological Engineering, vol. 36, no. 3, pp. 1609-1620, 2018.

[19] J. Yang, W. Lu, Y. Hu, M. Chen, and P. Yan, "Numerical simulation of rock mass damage evolution during deep- buried tunnel excavation by drill and blast," Rock Mechanics and Rock Engineering, vol. 48, no. 5, pp. 2045-2059, 2015.

[20] Y. Zhang, T. B. Zhao, A. Taheri, Y. L. Tan, and K. Fang, "Damage characteristics of sandstone subjected to pre-peak and post-peak cyclic loading," Acta Geodynamica et Geomaterialia, vol. 16, pp. 143-150, 2019.

[21] X. G. Zhao, M. Cai, J. Wang, and L. K. Ma, "Damage stress and acoustic emission characteristics of the Beishan granite," International Journal of Rock Mechanics and Mining Sciences, vol. 64, pp. 258-269, 2013a.

[22] X. G. Zhao, J. Wang, L. K. Ma, R. Su, M. Cai, and G. B. Wang, "Acoustic emission behaviors of the Beishan granite under uniaxial and triaxial compression conditions," in Proceedings of the 3rd ISRM SINOROCK Symposium, CRC Press/Balkema, London, UK, January 2013b.

[23] Z. L. Zhao, X. Wang, and Z. J. Wen, "Analysis of rock damage characteristics based on particle discrete element model," Geotechnical and Geological Engineering, vol. 36, pp. 897-904, 2018. 